\title{
Pulmonary Hypoplasia with Pulmonary Tuberculosis in Healthy Infant A Case Report:-
}

\author{
Sheikh Mushtaq ${ }^{1}$,Altaf Ahmad Bhat ${ }^{2}$, Mudasir Ahad Wani ${ }^{3}$,Adil Ramzan ${ }^{4}$
}

\begin{abstract}
A case of right sided pulmonary hypoplasia with tuberculosis is described. A 7 months male was admitted in our department with complaints of recurrent chest infections since birth. Clinical examination revealed smaller right hemithorax. Serial chest Xrays showed non progressive lesions over several months . Bronchoscopy and CT scan thorax confirmed the diagnosis of right sided pulmonary hypoplasia. CBNAAT of bronchial secretions and gastric aspirate was positive for Mycobacterium tuberculosis. It was not associated with any other developmental anomaly
\end{abstract}

Key words: - Pulmonary Hypoplasia, Pulmonary tuberculosis, Bronchoscopy, CT scan thorax.

\section{Introduction}

Pulmonary Hypoplasia is a rare clinical syndrome which occurs with incidence of 1 to 2 per 12,000 births and can manifest as respiratory distress at birth, in neonatal period or may be incidentally diagnosed afterwards depending upon the severity of Hypoplasia. Pulmonary Hypoplasia almost always occurs secondary to other intrauterine disorders that produce an impairment of normal lung development, Pulmonary Hypoplasia involves a decrease in both the number of alveoli (up to 67\%) and the number of airway generations (up to $50 \%)^{1}$. In Hypoplasia of lung there is decrease in number or size of airways, vessels and alveoli. Under development of alveolar tissue results in small fibrotic and non functioning lung. Bronchiectatic changes have also been reported in the hypoplastic lung ${ }^{2}$. This condition is frequently associated with other congenital anomalies. Common developmental anomalies associated with pulmonary hypoplasia involve urinary system, diaphragm, cardiovascular system (Tetralogy of Fallot) ${ }^{3,4,5}$, central nervous system (anencephaly and hydroencephaly $)^{6}$, as also musculoskeletal anomalies of thoracic cage, Klippel Feil syndrome and Down syndrome ${ }^{7}$.Here we report a clinical case of such variety where child was not well from birth and had repeated chest infections. We reported this baby as a case of pulmonary Hypoplasia with pulmonary tuberculosis. We stress on to search for tuberculosis when underlying pathology of respiratory distress may be different like in this case of hypoplasia of right lung which was infected with mycobacterium tuberculosis.

\section{Case presentation}

7 months old male baby born of non con-sanguineous marriage, born by LSCS term pregnancy, with birth weight of $3 \mathrm{kgs}$, birth order first, and had uneventful antenatal and postnatal history, exclusively breastfed and properly weaned was brought with complaints of fever since five day of moderate grade intensity and continuous nature, cough since five days, dry in nature and fast breathing since three days, baby had multiple episodes of respiratory infections managed as case of acute bronchiolitis at peripheral health center, no history of rash, no h/o suck rest suck cycle, baby had a history of tuberculosis contact. General examination was normal development consistent with age, immunized as per IAPS till date, BCG scar present, vital parameters were stable except baby was tachypneic and febrile with temperature of $100{ }^{\circ} \mathrm{F}$. On Systemic examination trachea was central in position mild chest asymmetry was noted smaller right hemithorax, with more inflated left side of chest, Examination of respiratory system revealed movements were diminished and percussion note was dull over the right hemithorax. On auscultation, air entry was very poor on right side with diffuse crepitations. Rest of systems were normal. Routine haematological investigations were within normal limits. Chest roentgenogram showed a right sided massive homogeneous ill-defined opacity in upper zone with overcrowding of ribs on right side and hypo aerated right lung Fig1. Shifting of the mediastinum to right side. The intercostal spaces on right side were narrowed. Left lung was overinflated. The lesions were non progressive on serial chest X-rays. CT Scan Thorax revealed marked asymmetry in thorax and showed hypo plastic right lung fig $2 \mathrm{a}, 2 \mathrm{~b}, 2 \mathrm{c}$. Bronchoscopy revealed the under development of right bronchial tree. However, normal development of tracheobronchial tree of left side was seen. Mountax test was significantly positive more than $10 \mathrm{~mm}$, bronchial secretion stained negative for AFB. Bonchial secretion and Gastric lavage for CBNAAT detected Rifampicin sensitive MTB. 


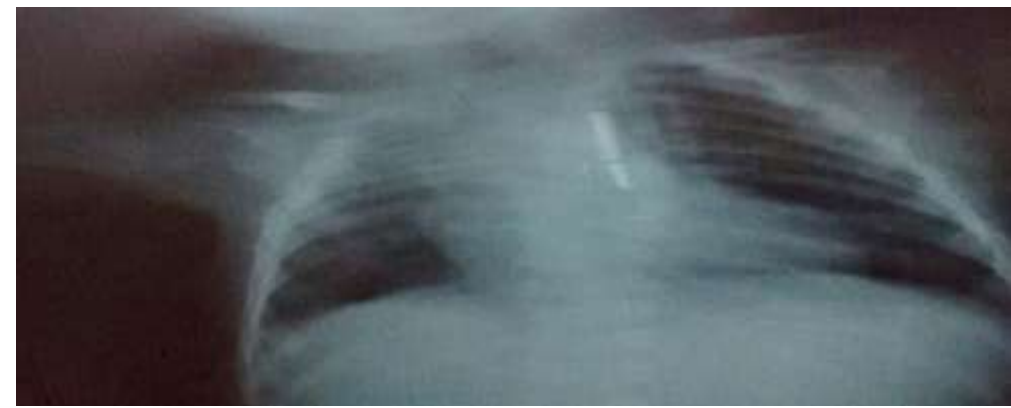

Fig no 1

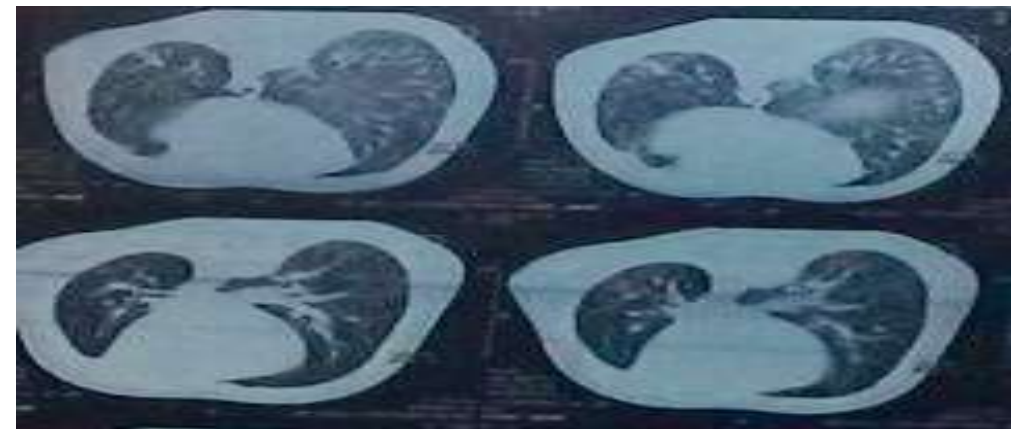

Fig no: 2a.

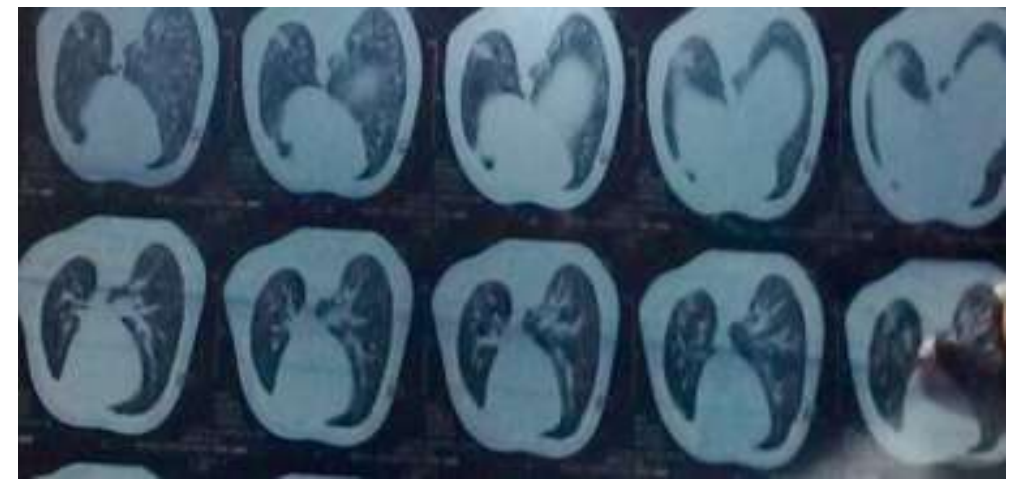

Fig no: 2 b.

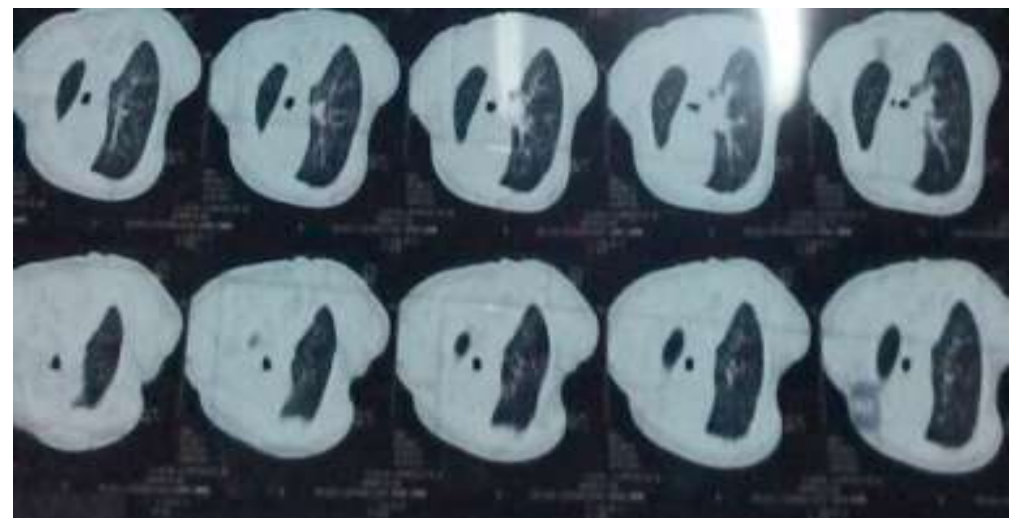

Fig no:2c.

\section{Discussion}

In utero, the fetal lungs are filled with fluid and gas exchange occurs via the placenta. Fetal lung fluid and fetal breathing movements are two important factors in the development of healthy newborn lungs ${ }^{8}$. There are 5 stages of lung development; embryonic, pseudo glandular, canalicular, saccular, and alveolar. The alveolar stage continues up to 2 years of age where the alveoli are continuing to septate and multiply ${ }^{9}$ Lung development continues into young adulthood with enlargement of the terminal bronchioles and alveoli. An arrest in 
development in any one of the stages, result in congenital pulmonary diseases. Any condition that produces oligo-hydramnios (e.g., fetal renal insufficiency or prolonged premature rupture of membranes) may also lead to diminished lung growth. In these conditions, airway and arterial branching are inhibited, thereby limiting the capacity for capillary and gas exchange surface area ${ }^{1,8,10}$

Development of the bronchial tree takes place at about 26th to 31st day of intrauterine life. Monaldi divided the mal-development of lung in four groups. Group I: No bifurcation of trachea; Group II: Only rudimentary main bronchus; Group III: Incomplete development after division of main bronchus; and Group IV: Incomplete development of subsegmental bronchi and small segment of the corresponding lobe. The present case belongs to the fourth group of Monaldi classification. According to Boyden ${ }^{11}$ there are three degrees of mal-development: (i) agenesis, in which there is complete absence of lung tissue, (ii) aplasia, in which rudimentary bronchus is present but no lung tissue is present, and (iii) hypoplasia, in which all the normal pulmonary tissues are present but are under-developed. Hypoplasia of the lung may be regarded as primary (idiopathic) or secondary (when it occurs in association with environmental factors or other congenital anamolies that may be implicated in its pathogenesis). The incidence of primary hypoplasia has been estimated to be 1 to 2 per 12,000 births. Several mechanisms have been implicated in secondary pulmonary hypoplasia including decreased hemithoracic volume, decreased pulmonary vascular perfusion, decreased fetal respiratory movement and decreased lung fluid. The basis of variation in morphologic findings of hypoplastic lung is related to severity and cause of hypoplasia as well as to the timing of the etiologic events that led to anomaly ${ }^{12}$.

Main differential diagnosis of hypoplastic lung is Swyer James syndrome. Swyer James syndrome is an uncommon abnormality characterized radiologically by hyperlucent lobe or lung and functionally by air trapping during expiration. There is substantial evidence that the syndrome is initiated by viral bronchiolitis. Although both conditions are associated with unilateral very low volume, patients with Swyer James syndrome characteristically demonstrate an air trapping on radiographs or HRCT scans performed at the end of maximal expiration ${ }^{13}$. Clinical findings depend on degree of pulmonary abnormality and presence of other congenital malformations.

Usually, however the patient is symptomatic. Physical examination characteristically reveals asymmetry of two sides of thorax, reduction in respiratory movements and absence of air entry in the affected side. This may be diagnosed incidentally during childhood when complicated by pulmonary infection ${ }^{14,15}$. Diagnosis may be established with help of chest x-ray, CT thorax, fiber optic bronchoscopy, and if possible pulmonary angiography and bronchography.

Treatment of hypoplasia is in form of medical as well as surgical care, both before and after delivery. Before delivery patient is treated medically with repeated amniofusions with or without the use of tocolytics, antibiotics and steroids. After delivery respiratory support is given ranging from oxygen to mechanical ventilation including ECMO (Extracorporeal membrane oxygenation). Dialysis may be required for support of renal function. Surfactant administration at $4 \mathrm{ml} / \mathrm{kg}$ improves survival rate. Surgical care consists of intrauterine vesicoamniotic shunts and endoscopic ablation of valves and PLUG (plug the lung until it grows) by fetoscopic tracheal occlusion with a clip. Post-delivery surgery can be done to correct diaphragmatic hernia, cystic adenomatoid malformations and decompresses pleural effusions. In our case we also started baby on Anti tubercular treatment.

\section{Refrenceses}

[1]. Nelson, textbook of pediatrics, respiratory system;19:1423-1424.

[2]. Calenoff L. Unilateral pulmonary hypoplsia in an adult. Am J Roentgenol. 1964; 91: 265-272.

[3]. Hislap A, Hey E, Reid L. The lungs in congenital bilateral renal agenesis and dysplasia. Arch Dis Chil. 1979; 54: 32-38.

[4]. Areechon W, Reid L, Hypoplasia of lung with congenital diaphragmatic hernia. Br Med. J. 1963; 1: 230-233.

[5]. Johnson RJ, Howorth SG. Pulmonary vascular and alveolar development in tetralogy of fallot: A recommendation for early correction. Thorax 1982; 37: 893-901.

[6]. Cooney TP, Thurlbeck, wm. Lung growth and development in

[7]. anencephly and hydranencephaly. Am Rev Respir Dis. 1985; 132:596-601.

[8]. Cooney TP, Thurlbeck WM, Pulmonary hypoplasia in Down syndrome. N Engl J Med 1982; 307: 1170-1173.

[9]. Kotecha S. Lung growth for beginners. Paediatr Respir Rev. 2000;1:308-313.

[10]. Joshi S, Kotecha S. Lung growth and development. Early Hum Dev. 2007;83:789-794.

[11]. Richard M.Cantor,P.David Sadowitz,respiratory emergencies.Neonatal emergencies 2010;3:67-68.

[12]. Boyden EA. Developmental anomalies of the lungs. Am J Surg. 1955; 89: 79-89.

[13]. Rutledge JC, Jensen P: Acinar dysplasia: A new form of pulmonary maldevelopment. Hum Pathol. 1986; 17: 1290.

[14]. Moore ADA, Godwin JD, Dietrich PA et al.: Swyer James Syndrome: CT fi ndings in eight patients. Am. J. Roentgenol. 1992; 158: 1211.

[15]. Page DV, Stocker JT: Anomalies associated with pulmonary hypoplasia. Am Rev Resp Dis. 1982; 125: 216.

[16]. Borja AR, Ransdell HT, Villa S. Congenital developmental arrest of lung. Am Thoracic Surg 1970; 10: 317. 